\title{
Characterization and Antioxidant Activity of Essential Oil of Four Sympatric Orchid Species
}

\author{
Francesco Saverio Robustelli della Cuna ${ }^{1,2, *}$, Jacopo Calevo ${ }^{3,4} \oplus$, Elia Bari ${ }^{2}{ }^{\mathbb{D}}$, \\ Annalisa Giovannini ${ }^{3}$ (D) , Cinzia Boselli ${ }^{2}$ and Aldo Tava ${ }^{1}$ (D) \\ 1 CREA Research Centre for Animal Production and Aquaculture, Viale Piacenza 29, 26900 Lodi, Italy; \\ aldo.tava@crea.gov.it \\ 2 DDS Department of Drug Sciences, University of Pavia, Viale Taramelli 12, 27100 Pavia, Italy; \\ elia.bari@unipv.it (E.B.); cinzia.boselli@unipv.it (C.B.) \\ 3 CREA Research Centre for Vegetable and Ornamental Crops, Corso degli Inglesi 508, 18038 Sanremo (IM), \\ Italy; jacopo.calevo@unito.it (J.C.); annalisa.giovannini@crea.gov.it (A.G.) \\ 4 DBIOS Department of Life Sciences and Systems Biology, University of Torino, Viale Mattioli 25, \\ 10125 Torino, Italy \\ * Correspondence: fsaveriorobustelli@unipv.it
}

Received: 18 September 2019; Accepted: 24 October 2019; Published: 28 October 2019

\begin{abstract}
The volatile fractions from fresh inflorescences of naturally growing orchids Anacamptis coriophora (L.) R. M. Bateman, Pridgeon \& M. W. Chase subsp. fragrans (Pollini), Anacamptis pyramidalis (L.) R. Ophrys holosericea (Burm.) Greuter and Serapias vomeracea (Burm. f.) B. were isolated by steam distillation and analyzed by GC/FID and GC/MS. Saturated hydrocarbons were quantified as the major constituents of the volatile fraction (47.87-81.57\% of the total essential oil), of which long-chain monounsaturated hydrocarbons accounted from $9.20 \%$ to $32.04 \%$ of the total essential oil. Double bond position in linear alkenes was highlighted by dimethyl disulfide derivatization and MS fragmentation. Aldehydes (from 3.45 to $18.18 \%$ of the total essential oil), alcohols (from $0.19 \%$ to $13.48 \%$ ), terpenes (from 0.98 to $2.50 \%$ ) and acids ( 0.30 to $2.57 \%$ ) were also detected. These volatiles compounds may represent a particular feature of these plant species, playing a critical role in the interaction with pollinators. DPPH assay evaluating the antioxidant activity of the essential oils was carried out, showing a dose-dependent antioxidant activity.
\end{abstract}

Keywords: Anacamptis coriophora; Anacamptis pyramidalis; Ophrys holosericea; Serapias vomeracea; alkenes; volatiles; pollinators

\section{Introduction}

Pollination of flowers by animals is often influenced by a wide variety of volatile molecules [1,2]. The floral scent in plants has the primary aim to attract and guide pollinators [3,4], playing a critical role both in long- and short-distance attraction [2,5,6]. In fact, bees learn odours easier and more rapidly than colours [3,7]. Furthermore, the floral scent may thus influence/drive pollinator constancy [3,8], which ensures pollen transfer, reduces pollen loss and contributes to maintaining both the plant reproductive fitness and their barriers among species [9,10]. Additional functions of floral volatile chemicals occur as defensive and protective mechanisms vs. biotic and abiotic stresses [11-13]. This may explain the wide variety of volatiles fragrances emitted by orchids acting as key characters to drive pollinators when food or sexual deception takes place [2].

Orchidaceae is considered one of the well-represented flowering plant families, worldwide distributed accounting approximately 28,000 species [14]. This abundance leads to a great complexity of floral scents; in fact, orchids can potentially produce almost all the fragrances occurring in nature [15]. 
This wide variety of floral scents is primarily due to the combination of the great number of orchid species and of the evolution of pollination systems. The mechanisms of deception in orchids include generalized food deception, food-deceptive floral mimicry, brood-site imitation, shelter imitation, pseudo-antagonist, rendezvous attraction and sexual deception, where generalized food deception is the most common mechanism (38 genera) followed by sexual deception (18 genera) [16,17]. In the Orchidoideae subfamily, in particular, consisting of 7 subtribes and about 3630 species [18], the sexual deception mechanism can be recognized for orchid genera such as Drakea or Ophrys [18]. Furthermore, orchids using food-deceptive strategy show flowers resembling those of rewarding co-occurring species [19].

Italy hosts about 236 orchid species [20], that frequently co-occur in the same habitat and population [21]. A peculiar pollination strategy is the sexual deception of the genus Ophrys: in this orchid genus the shape of the labellum looks like the female abdomen of the bee pollinator species and the floral scent contains interactive chemicals resembling the sex pheromones of pollinators. These intriguing visual and olfactory signals are, therefore, of critical importance to driving pollinator choices [22]. On the other hand, genera such as Orchis, Dactylorhiza and some Anacamptis employ a generalized food-deceptive strategy [19], in which these flowers provide floral cues indicating a food reward while animal pollination is achieved without providing nectar, pollen or other food rewards. On the contrary species of the genus Serapias employ an unusual pollination strategy called shelter deception. In fact, these flowers, nectarless and not so brightly coloured, form a small tube used by pollinators as a refuge during cold or rainy weather to rest or sleep [23-25].

The aim of the present investigation was to isolate and compare the essential oils from inflorescences of four sympatric orchid species (Anacamptis coriophora (L.) R.M. Bateman, Pridgeon \& M. W. Chase subsp. fragrans (Pollini), Anacamptis pyramidalis (L.) R., Serapias vomeracea (Burm. f.) B. and Ophrys holosericea (Burm) Greuter), co-occurring in the same natural site in Italy, in order to characterize their chemical composition and antioxidant activity.

\section{Results}

The essential oil obtained by steam distillation from fresh inflorescences were evaluated as $1.3 \mathrm{mg}$ for A. coriophora subsp. fragrans, $1.8 \mathrm{mg}$ for A. pyramidalis, $2.6 \mathrm{mg}$ O. holosericea and $3.4 \mathrm{mg}$ for S. vomeracea, respectively. The yields were evaluated as $0.03 \%, 0.02 \%, 0.52 \%$ and $0.10 \%$ (weight/fresh weight basis), respectively. Table 1 shows the results of qualitative and quantitative essential oil analyses on the Elite- 5 MS column. The compounds are listed in order of their elution time and reported as percentages of the total essential oil. The total number of peaks for A. coriophora subsp. fragrans was 60 with number of identified peak of 43 (72\% identification), A. pyramidalis was 58 with number of identified peak of 45 (78\% identification). O. holosericea was 59 with number of identified peak of 49 (83\% identification), S. vomeracea was 65 with number of identified peak of 59 ( $91 \%$ identification). As evidenced, the main represented volatiles constituents are saturated hydrocarbons, especially in A. coriophora subsp. fragrans followed by S. vomeracea, O. holosericea and A. pyramidalis, and unsaturated hydrocarbons mainly present in $O$. holosericea essential oil. Differences in the qualitative and quantitative composition of the volatile essential oils obtained from the four sympatric Italian orchids have been observed. 
Table 1. Percentage composition of the volatile fraction from inflorescences of A coriophora subsp. fragrans, A. pyramidalis, O. holosericea and S. vomeracea.

\begin{tabular}{|c|c|c|c|c|c|c|}
\hline \multirow[b]{2}{*}{ Compound } & \multirow[b]{2}{*}{$\mathbf{R I}^{\mathrm{a}}$} & \multirow[b]{2}{*}{$\mathbf{R I}^{\mathbf{b}}$} & \multicolumn{4}{|c|}{ Percentage Peak Area } \\
\hline & & & $\begin{array}{l}\text { A. coriophora } \\
\text { subsp. Fragrans }\end{array}$ & A. pyramidalis & O. holosericea & S. vomeracea \\
\hline Hexanal & 801 & 799 & $\operatorname{tr}$ & 0.30 & $\operatorname{tr}$ & 0.21 \\
\hline 2-Methyl-2-pentenal & 821 & 829 & - & 0.16 & 0.30 & 0.24 \\
\hline Diacetone alcohol & 841 & 844 & - & 0.24 & 0.37 & 1.03 \\
\hline Heptanal & 901 & 901 & 0.17 & 4.02 & 1.39 & 1.57 \\
\hline Nonane & 1000 & 999 & 0.45 & - & 0.08 & 0.06 \\
\hline Octanal & 1001 & 1003 & - & - & 0.07 & 0.22 \\
\hline Benzyl alcohol & 1032 & 1033 & $\operatorname{tr}$ & 1.13 & 2.59 & $\operatorname{tr}$ \\
\hline Phenylacetaldehyde & 1042 & 1042 & 0.70 & 3.82 & 2.07 & 3.91 \\
\hline 2,4-Dimethyldecane & 1067 & 1068 & 0.56 & 0.55 & 1.24 & 0.57 \\
\hline 3,5-Octadien-2-one & 1072 & 1071 & - & - & 0.08 & - \\
\hline Heptanoic acid & 1083 & 1083 & 0.14 & 1.41 & - & 0.37 \\
\hline Octanoic acid & 1173 & 1173 & - & - & - & 0.07 \\
\hline 1-Dodecene & 1192 & 1192 & - & - & - & 0.19 \\
\hline Dodecane & 1200 & 1200 & 0.47 & 0.42 & 0.45 & 0.26 \\
\hline Decanal & 1204 & 1206 & - & 0.17 & 0.15 & 0.49 \\
\hline Anisaldehyde & 1251 & 1253 & 0.68 & - & - & - \\
\hline Nonanoic acid & 1275 & 1272 & 0.16 & 1.16 & $\operatorname{tr}$ & 0.71 \\
\hline Thymol & 1277 & 1281 & 0.36 & 0.30 & 0.66 & 0.28 \\
\hline Undecanal & 1307 & 1307 & - & $\operatorname{tr}$ & 0.36 & 1.35 \\
\hline 2,5-Dimethoxy benzyl alcohol & 1328 & 1327 & 0.19 & - & 0.14 & - \\
\hline$\alpha$-Copaene & 1376 & 1376 & 0.26 & 0.45 & 0.56 & $\operatorname{tr}$ \\
\hline 1-Tetradecene & 1390 & 1392 & - & $\operatorname{tr}$ & - & 0.39 \\
\hline Tetradecane & 1400 & 1400 & 0.45 & 0.54 & 0.50 & 1.68 \\
\hline Dodecanal & 1412 & 1409 & - & 0.05 & 0.26 & 0.38 \\
\hline Methyl-p-methoxycinnamate & 1617 & 1614 & 0.58 & - & - & - \\
\hline Heptadecane & 1700 & 1700 & 0.24 & 0.24 & 0.45 & 0.65 \\
\hline Pentadecanal & 1713 & 1713 & - & 0.11 & - & 0.28 \\
\hline 1-Heptadecene & 1755 & 1748 & 0.06 & - & - & 0.40 \\
\hline Octadecane & 1800 & 1800 & - & - & - & 0.08 \\
\hline Nonadecane & 1900 & 1900 & 20.51 & 2.26 & 0.56 & 2.45 \\
\hline Isophytol & 1944 & 1949 & - & 1.47 & $\operatorname{tr}$ & 0.84 \\
\hline Palmitic acid & 1950 & 1960 & - & - & - & 0.77 \\
\hline Eicosane & 2000 & 1999 & 1.56 & 0.14 & - & 0.17 \\
\hline Octadecanal & 2021 & 2020 & 0.19 & 1.44 & 1.00 & 0.93 \\
\hline 9-Heneicosene & 2071 & 2073 & - & - & - & 0.71 \\
\hline Heneicosane & 2100 & 2100 & 25.10 & 7.50 & 4.34 & 5.68 \\
\hline Docosane & 2200 & 2199 & 0.96 & - & 1.01 & 0.80 \\
\hline 11-Tricosene & 2261 & 2265 & 0.17 & - & 0.15 & 0.65 \\
\hline 9-Tricosene & 2279 & 2274 & 1.42 & - & 3.19 & 1.19 \\
\hline 7-Tricosene & 2287 & 2280 & - & - & 2.72 & 1.18 \\
\hline Tricosane & 2300 & 2300 & 17.16 & 17.17 & 27.71 & 14.21 \\
\hline Tetracosane & 2400 & 2400 & 0.76 & - & 1.58 & 1.90 \\
\hline 11-Pentacosene & 2469 & 2469 & - & - & 1.77 & - \\
\hline 9-Pentacosene & 2474 & 2474 & 3.39 & 4.69 & 2.95 & 3.92 \\
\hline 7-Pentacosene & 2483 & 2482 & - & $\operatorname{tr}$ & 16.60 & 2.48 \\
\hline Pentacosane & 2500 & 2500 & 9.31 & 16.24 & 6.84 & 17.59 \\
\hline Hexacosane & 2600 & 2600 & 0.27 & 0.47 & - & 0.85 \\
\hline 9-Heptacosene & 2676 & 2675 & 2.30 & 3.90 & 2.17 & 2.87 \\
\hline 7-Heptacosene & 2683 & 2681 & 0.34 & 1.38 & 2.36 & 3.71 \\
\hline Heptacosane & 2700 & 2699 & 3.43 & 6.04 & 2.22 & 4.99 \\
\hline
\end{tabular}

$\mathrm{RI}^{\mathrm{a}}$ : Retention Indices from literature [26]. RI ${ }^{\mathrm{b}}$ : Retention Indices calculated by GC/FID using n-alkane series (from $\mathrm{C}_{8}$ to $\left.\mathrm{C}_{23}\right)$ under the same analytical conditions as for samples. tr, traces $(<0.01 \%) ;>0.01 \%$ quoted to nearest $0.01 \%$. 


\subsection{Anacamptis Coriophora subsp. Fragrans}

Major constituents of the volatile fractions of this orchid species were found to be saturated hydrocarbons $(81.57 \%$ of the total essential oil), from which heneicosane $(25.10 \%)$, nonadecane $(20.51 \%)$, tricosane $(17.16 \%)$, pentacosane $(9.31 \%)$ and heptacosane $(3.43 \%)$ are the most abundant compounds. A series of unsaturated linear chain hydrocarbons were identified, of which 9-pentacosene and 9-heptacosene represent the $3.39 \%$ and $2.30 \%$ of the total volatiles, followed by 9-tricosene and 1-hexadecene accounting for $1.42 \%$ and $1.21 \%$ of the total essential oil, respectively. Aldehydes are present in the percentage of $3.45 \%$, being nonanal $(1.61 \%)$, phenylacetaldehyde $(0.70 \%)$ and anisaldehyde $(0.68 \%)$ the most represented. Alcohols $(0.19 \%)$ and terpenes $(0.98 \%)$ consisted of 2,5-dimethoxybenzyl alcohol $(0.19 \%)$, thymol $(0.36 \%)$ and $\alpha$-copaene $(0.26 \%)$, respectively.

\subsection{Anacamptis Pyramidalis}

Major constituents of the volatile fractions of A. pyramidalis were found to be saturated hydrocarbons accounting for $52.43 \%$ of the total essential oil. Tricosane $(17.17 \%)$, pentacosane $(16.24 \%)$, heneicosane $(7.50 \%)$ and heptacosane $(6.04 \%)$ are the most abundant constituents of this class of compounds. Aldehydes present as $16.19 \%$ were basically represented by nonanal $(5.44 \%)$, heptanal $(4.02 \%)$ phenylacetaldehyde (3.82\%) and octadecanal (1.44\%). Alcohols (13.48\%) consist of 2-phenylethanol (12.11\%) followed by benzyl alcohol (1.13\%). A series of unsaturated linear chain hydrocarbons $(10.34 \%)$ was instead identified with 9-pentacosene and 9-heptacosene as the $4.69 \%$ and $3.90 \%$, followed by 7 -heptacosene evaluated as $1.38 \%$ of the total essential oil. Acids are also detected as $2.57 \%$, being heptanoic acid $(1.41 \%)$ the most abundant followed by nonanoic acid $(1.16 \%)$. Terpenes $(2.50 \%)$ are mainly represented by $\alpha$-copaene $(0.45 \%)$, thymol $(0.30 \%)$ and $\alpha$-cadinene $(0.14 \%)$.

\subsection{Ophrys Holosericea}

Saturated hydrocarbons, accounting for $47.87 \%$ of the total essential oil were found to be the major constituents also of $O$. holosericea volatiles. Tricosane $(27.71 \%)$, pentacosane $(6.84 \%)$, heneicosane $(4.34 \%)$, heptacosane $(2.22 \%)$ are the most abundant compounds. A series of unsaturated linear chain hydrocarbons $(32.04 \%)$ was also identified, of which 7-pentacosene $(16.60 \%)$ was the major represented, followed by 9-tricosene (3.19\%), 9-pentacosene (2.95\%), 7-tricosene (2.72\%), 7-heptacosene $(2.36 \%)$, 9-heptacosene (2.17\%) and 11-pentacosene (1.77\%). Aldehydes (10.74\% of the total essential oil) consist mainly of nonanal $(4.65 \%)$, phenylacetaldehyde $(2.07 \%)$, heptanal $(1.39 \%)$ and octadecanal $(1.00 \%)$. Alcohols $(3.20 \%$ of the total) are represented by benzyl alcohol $(2.59 \%)$ and terpenes (1.74\% of the total) by thymol $(0.66 \%), \alpha$-copaene $(0.56 \%)$ and $\gamma$-muurolene $(0.48 \%)$.

\subsection{Serapias Vomeracea}

More than $50 \%$ of the S. vomeracea volatile fraction consists of saturated hydrocarbons accounting for $53.29 \%$ of the total essential oil. Pentacosane (17.59\%), tricosane $(14.21 \%)$, heneicosane $(5.68 \%)$, heptacosane $(4.99 \%)$, nonadecane $(2.45 \%)$, tetracosane $(1.90 \%)$ and tetradecane $(1.68 \%)$ were the most representative compounds. Monounsaturated linear chain hydrocarbons $(18.63 \%)$ were also identified, of which the 9- and 7- isomers were the most represented. In details the rank order is: 9-pentacosene $(3.92 \%)>7$-heptacosene $(3.71 \%)>9$-heptacosene $(2.87 \%)>7$-pentacosene $(2.48 \%)>9$-tricosene $(1.19 \%)$ $>7$-tricosene $(1.18 \%)$. Aldehydes accounting for $18.18 \%$ of the total volatiles consist mainly of nonanal (7.87\%), phenylacetaldehyde (3.91\%), heptanal $(1.57 \%)$, undecanal $(1.35 \%)$ and octadecanal $(0.93 \%)$. Acids $(1.92 \%$ of the total) are represented by palmitic acid $(0.77 \%)$, nonanoic acid $(0.71 \%)$ and heptanoic acid $(0.37 \%)$. Terpenes $(2.44 \%)$ account for trans- $\beta$-farnesene $(0.84 \%), \gamma$-muurolene $(0.39 \%)$ and thymol $(0.28 \%)$. The only alcohol found in S. vomeracea volatile fraction was diacetone alcohol as $1.03 \%$ of the total essential oil. 


\subsection{Venn's Diagram}

Figure 1 shows the Venn's diagram [27] in which 22 compounds are shared among all the 4 sympatric Italian orchids. Even if just a few, some peculiarities were found to be species-specific. In detail, four compounds were found only in A. coriophora subsp. fragrans, i.e., creosol, anisaldehyde, $\gamma$-eudesmol and methyl-p-methoxycinnammate, although poorly represented $(<1 \%$ of the total essential oil). In $A$. pyramidalis only one compound, 2-phenylethanol (12.11\% of the total essential oil), seems to be species-specific, further characterizing this species. O. holosericea showed to have four peculiar compounds, i.e., heptanol, 3.5-octadien-2-one, 2.3-dimethyldecane and 11-pentacosene. It should be stressed that only the latter one is present with a valuable amount, reaching $1.77 \%$ of the total essential oil. On the contrary, S. vomeracea was the species showing eight unique chemicals, being trans- $\beta$-farnesene, that represents the $50 \%$ of total terpenes, palmitic acid and 9 -heneicosene the most abundant reaching the $0.84 \%, 0.77 \%$ and $0.71 \%$ of the total essential oil, respectively.

\subsection{DPPH Assay}

All samples demonstrated a good, dose-dependent, antioxidant activity by the DPPH assay (Figure 2). ANOVA analysis evidenced that the ROS-scavenging activity is strongly influenced both by the sample and concentrations tested $(p<0.0001)$. In particular, $O$. holosericea shows the strongest antioxidant activity, especially at a concentration of $1.5 \mathrm{mg} / \mathrm{mL}$. For $S$. vomeracea, the concentration did not influence the antioxidant activity $(p>0.05)$.

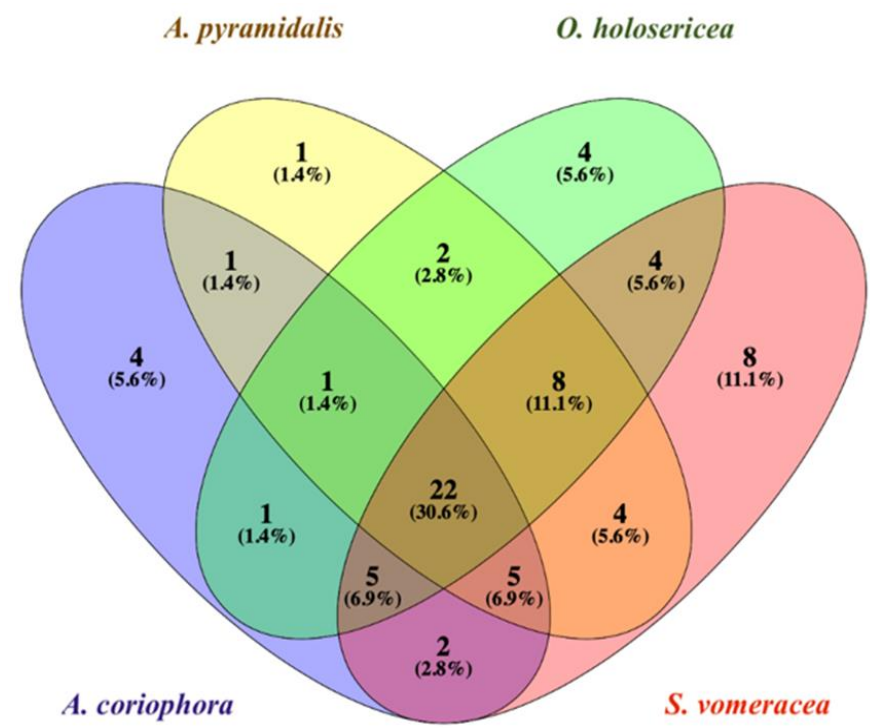

Figure 1. Venn's diagram shows both the number of compounds shared and unshared/peculiar among the four orchid species. Percentages are referred to the total number of compounds found, not to the relative abundance [27]. 


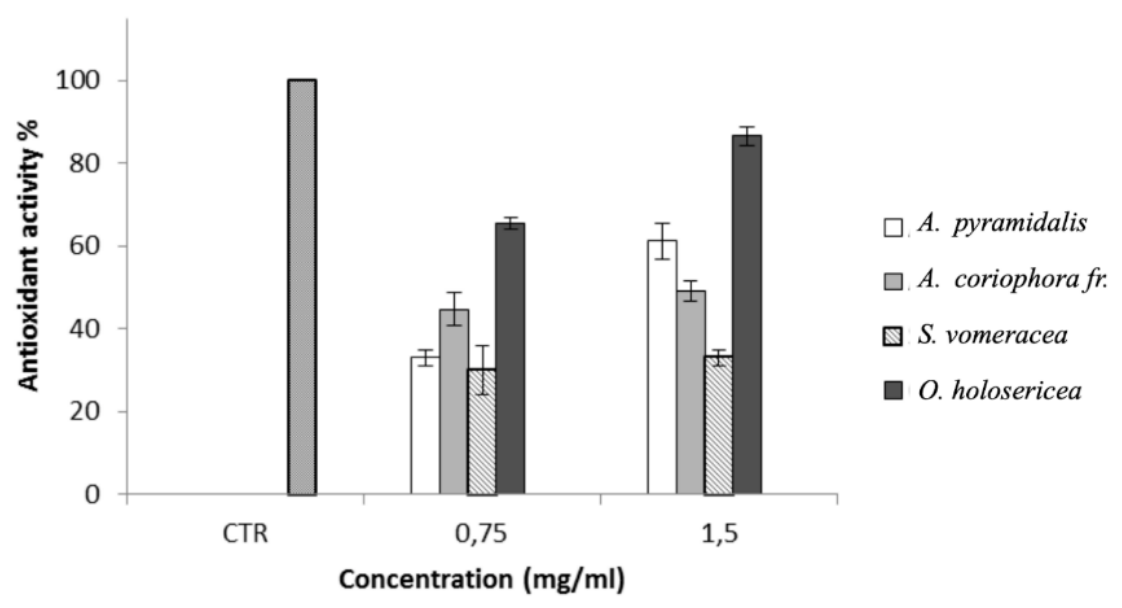

Figure 2. ROS-scavenging activity (\%) of the tested extracts.

\section{Discussion}

A high percentage of saturated hydrocarbons has been detected in the volatile fraction of all the four Italian sympatric orchid species. The presence of saturated hydrocarbons in higher percentage with respect to other published research [28] is probably due to the different extraction procedures like solid-phase microextraction that work at lower extraction temperatures. In detail, a series of homologous linear chain compounds ranged from $C_{9}$ to $C_{29}$ have been reported for all the terrestrial and epiphytic orchids. The presence of hydrocarbons as allelochemicals is associated with epicuticular wax chemistry playing an important role in plant/herbivore interactions. Saturated alkanes exerted an interesting, although limited, activity in pollinator deception in different floral species [25,29-31].

The position of the double bond in linear alkene isomers was determined by GC/MS after iodine-catalyzed reaction with dimethyl disulfide. Derivatization procedure was applied to alkene mixtures, which have chemotaxonomic value for the pollinator populations. Linear chain monounsaturated hydrocarbons were previously identified in several orchid species with a high content of these compounds in flowers [30]. Although these compounds seem not to act are as specific contributors to the aroma of the plant, they might be crucial in modulating plant-herbivore interaction [32]. In fact, several studies demonstrated that this class of compounds is endowed with an interesting, although limited, activity in pollinator deception in Orchidaceae [21,31]. Furthermore, multifactorial mechanisms involved in protection actions from environmental factors such as water loss, thermal- or UV-related stress, seem to be related to the occurrence of hydrocarbons [30,32].

Another class of substances that might be involved in plant-insect interaction is reported to be benzenoids [33,34]. A pyramidalis, a specialized species and mainly dependent on butterflies for pollination [35-38], shows a strong presence of 2-phenylethanol (12.11\% of the total volatiles) in its flower's scent compared to the other orchis species (see Table 1). It should be stressed that benzenoids play a critical role in pollinator attraction strategy of A. pyramidalis, as well as those of two other terrestrial orchids, Nigritella nigra (today accepted as Gymnadenia nigra) (L) Reichb. $\mathrm{f}$. (2-phenylethanol) [15,39] and Gymnadenia conopsea (L) Br.R., (benzyl acetate) [15]. Given the volatile extract's composition, which included ROS-scavenging compounds, the antioxidant activity for each extract has been evaluated by DPPH method. All samples demonstrated a good antioxidant activity that is probably related to the presence of benzyl alcohol (A. pyramidalis $1.13 \%$, O. holosericea $2.59 \%$ ) and phenylacetaldehyde (A. coriophora subsp. fragrans $0.70 \%$, A. pyramidalis $3.82 \%$, O. holosericea $2.07 \%$ and S. vomeracea 3.91\%) as previously reported for essential oils from Laurus nobilis and Fagopyrum species [40,41], to the presence of thymol (A. coriophora subsp. fragrans $0.36 \%$, A. pyramidalis $0.30 \%$, O. holosericea $0.66 \%$ and S. vomeracea $0.28 \%$ ) and $\alpha$-copaene (A. coriophora subsp. fragrans $0.26 \%$, A. pyramidalis $0.45 \%$ and $O$. holosericea $0.56 \%$ ) as reported for essential oil from Cinnamodendron dinisii and Siparuna guianensis [42,43]. However, even if benzenoids have been observed to be predominant 
in specialist butterfly-pollinated flower scents, these compounds have been also found in generalist plants, suggesting that they might be emitted by both specialists and generalists [44]. It should be stressed that differences in floral scents, visual attraction and reward systems are decisive for chemical communication in pollination strategies of sympatric orchids to guarantee pollination efficiency and fidelity.

In detail, Ophrys flowers act as "false female" mimicking her visual, tactile and olfactory stimuli, so male pollinators attempt to copulate with the orchid labellum removing and delivering pollen, a process termed pseudocopulation. It should be noticed that the complex blend of different odours mimicking female pheromones mainly consists of long-chain alkanes and alkenes derivatives and that the relative alkanes and alkenes abundance makes each floral scent unique resulting in different pollinator species attraction $[22,30]$.

As regards $S$. vomeracea, its flowers form a small tube, which pollinators use basically as nest-replacement or refugee during rainy weather, although the pollination strategy of this orchid relies not only in the floral shape but also in the olfactory attractors to assure sufficient degree of pollinator fidelity; in fact both visual and olfactory signals are of critical importance in pollinator choice. Again, according to the literature [45] alkanes and alkenes have been found to be very important volatile components in this orchid species scent as reported in Table 1. In fact, a solitary bee such as Megachile rotundata has been found to mark its nest with an olfactory trace consisting of a mixture of alkanes and alkenes similar to that present in the Serapias and Ophrys scents [30].

Another class of substances that might be involved in plant-insect interaction is reported to be benzenoids [33,34]. A. pyramidalis, a specialized species and mainly dependent on butterflies for pollination [35-38], shows a strong presence of 2-phenylethanol in its flower's scent as reported (see Table 1). It should be stressed that benzenoids play a critical role in pollinator attraction strategy of A. pyramidalis, as well as those of two other terrestrial orchids, Nigritella nigra (today accepted as Gymnadenia nigra) (L) Reichb. f. (2-phenylethanol) [15,39] and Gymnadenia conopsea (L) Br.R., (benzyl acetate) [15].

However, even if benzenoids, in this case mainly 2-phenylethanol, have been observed to be predominant in specialist butterfly-pollinated flower scents, these compounds have been also found in generalist plants, suggesting that they might be emitted by both specialists and generalists [44].

Among the species investigated $A$. coriophora subsp. fragrans can be occasionally pollinated by Lepidoptera (even if they are not the main pollinators), as shown in Table 2 [46].

Table 2. Relationship between each sympatric Italian orchid and its pollinators, according to GIROS [46].

\begin{tabular}{|c|c|c|c|c|}
\hline Species & Lepidotpera & Diptera & Hymenoptera & Coleoptera \\
\hline Anacamptis coriophora subsp. Fragans & $\begin{array}{l}\text { Nymphalidae } \\
\text { Zygaenidae }\end{array}$ & $\begin{array}{l}\text { Tachinidae } \\
\text { Bombyliidae }\end{array}$ & $\begin{array}{l}\text { Apidae } \\
\text { Halictidae } \\
\text { Vespidae }\end{array}$ & Oedemeridae \\
\hline Anacamptis pyramidal & $\begin{array}{l}\text { Arctiidae } \\
\text { Crambidae } \\
\text { Hesperidae } \\
\text { Lycaenidae } \\
\text { Nymphalidae } \\
\text { Noctuidae }\end{array}$ & $\begin{array}{l}\text { Bombyliidae } \\
\text { Conopidae } \\
\text { Empididae }\end{array}$ & Apidae & Oedemeridae \\
\hline Ophrys holosericea & - & - & $\begin{array}{c}\text { Apidae } \\
\text { Formicidae }\end{array}$ & Rutelidae \\
\hline Serapias vomeracea & - & - & $\begin{array}{c}\text { Apidae } \\
\text { Crabronidae } \\
\text { Eumenidae } \\
\text { Halictidae } \\
\text { Megachilidae }\end{array}$ & Scarabaeidae \\
\hline
\end{tabular}


Unlike A. pyramidalis, in A. coriophora subsp. fragrans alkanes and alkenes are the main constituents of the scent. The results reported in the present paper are different from those reported in the scarce literature available data [47-49]. In this investigation, we analyzed pre-pollinated flowers of $A$. coriophora subsp. fragrans chemotype europaeus, while both inflorescences and mature seeds of $A$. coriophora subsp. fragrans chemotype africanus [47], or inflorescences of $A$. coriophora subsp. coriophora [48], respectively, were used by other Authors.

In conclusion keeping in mind that these four orchids colonize the same environment, bloom in the same time and share also some pollinators, the data reported in the present paper strongly suggest that each species may attain a peculiar combination of olfactory, tactile and/or visual floral signs suitable to explain different interactive communication systems between plants and pollinators. Furthermore, it is reasonable to assess that each orchid species is able to gain especially through different signals a sufficient level of pollinator fidelity and thus maintain its genetic identity even in a population of admixed orchid species

\section{Materials and Methods}

\subsection{Plant Material}

Inflorescences of the four orchid species were collected in May 2016 in Pompeiana (Imperia, Italy, 438,547 N 78,909 E) according to the regional law and with the legal permission of Regional Authorities (Region Liguria, Prot. n. PG/2016/104503). Plants were identified according to Chase and colleagues [48]. A type specimen for each species is deposited in the living collection of CREA-OF (Sanremo, Italy) with the accession numbers ANcf01, ANpy01, OPho01, and SEvo01 for A. coriophora subsp. fragrans, A. pyramidalis, O. holosericea and S. vomeracea, respectively. The flowers were cut and immediately placed in a pyrex bottle containing $100 \mathrm{~mL}$ of methylene chloride as a preservative agent and stored at $-20^{\circ} \mathrm{C}$.

\subsection{Isolation of Volatile Fraction}

Flowers of A. coriophora subsp. fragrans (4.6 dried g), A. pyramidalis (9.3 dried g), O. holosericea ( 0.5 dried g) and $S$. vomeracea ( 3.3 dried g), to which ethyl decanoate was added as internal standard, were steam distilled together with methylene chloride in a Clevenger-type apparatus for $1 \mathrm{~h}$. The distillate, saturated with $\mathrm{NaCl}$, was extracted with freshly distilled diethyl ether $(3 \times 100 \mathrm{~mL})$, dried over anhydrous $\mathrm{Na}_{2} \mathrm{SO}_{4}$ concentrated at first with a rotary evaporator and finally using a gentle stream of $\mathrm{N}_{2}$ and then analyzed by GC/FID and GC/MS.

\subsection{Fractionation and Alkylthiolation of Alkenes}

A portion of the essential oil from each sample was placed onto a glass column $(7 \times 30 \mathrm{~mm})$ of silica gel 60, 230-400 mesh (Merck, Milano, Italy), preconditioned with pentane [29]. The non-polar fraction was eluted with $2 \mathrm{~mL}$ of pentane and used for the determination of double bond position in alkenes by alkylthiolation according to reported method [50].

\subsection{GC/FID Analysis}

The analyses were carried out using a Hewlett Packard model 5890 GC, equipped with Elite-5MS (5\% phenyl methyl polysiloxane, Supelco, Sigma Aldrich, Milano, Italy) capillary column of $(30 \mathrm{~m} \times 0.32 \mathrm{~mm}$ i.d.) and film $0.32 \mu \mathrm{m}$ thick. The carrier gas was He at a flow of $1 \mathrm{~mL} / \mathrm{min}$. One $\mu \mathrm{L}$ aliquots of each essential oil were manually injected in "split" mode (30:1). The oven temperature program included an initial isotherm of $40^{\circ} \mathrm{C}$ for $5 \mathrm{~min}$, followed by a temperature ramp to $260^{\circ} \mathrm{C}$ at $4^{\circ} \mathrm{C} / \mathrm{min}$, and a final isotherm at this temperature for $10 \mathrm{~min}$. Injector and detector temperatures were set at 250 and $280^{\circ} \mathrm{C}$, respectively. 


\subsection{GC/MS Analysis}

The analyses were carried out using a GC Model 6890 N, coupled to a benchtop MS Agilent 5973 Network, equipped with the same capillary column and following the same chromatographic conditions used for the GC/FID analyses. The carrier gas was He at a constant flow of $1.0 \mathrm{~mL} / \mathrm{min}$. The essential oils were diluted prior to analysis $(1 \mathrm{mg} / 10 \mathrm{~mL}$ in $n$-hexane), and $1.0 \mu \mathrm{l}$ of the diluted solution was manually injected into the GC system with a split ratio of 30:1. The ion source temperature was set at $200{ }^{\circ} \mathrm{C}$, while the transfer line was at $300{ }^{\circ} \mathrm{C}$. The acquisition range was $40-500 \mathrm{amu}$ in electron-impact (EI) positive ionization mode using an ionization voltage of $70 \mathrm{eV}$.

\subsection{Identification and Quantification of the Essential Oil Components}

The identification of the essential oil volatile components was performed by their retention indices (RI) and their mass spectra, and by comparison with a NIST 98 and Wiley 5 MS libraries, as well as with literature data [26]. Retention indices were calculated by an Elite-5MS capillary column using a series of n-alkanes $\left(C_{8}-C_{23}\right)$ under the same GC conditions as for samples [51]. The relative amount of each individual component of the essential oil was expressed as percent peak area relative to the total peak area from GC/FID analyses of the whole extract.

\subsection{DPPH Assay}

The ROS-scavenging activity of the essential oils was evaluated by the DPPH (2,2-diphenyl-2 picrylhydrazyl hydrate) method according to the previously described method with slight modifications [52-54]. At first, the essential oils were solubilized in dimethyl sulfoxide and then diluted in methanol at final concentrations of 1.5 and $0.75 \mathrm{mg} / \mathrm{mL} .270 \mu \mathrm{L}$ of DPPH $(0.028 \% w / v$ in methanol $)$ was mixed with $30 \mu \mathrm{L}$ of each sample. Reaction mixtures were incubated in the dark for 20 min at room temperature before measuring the absorbance at $517 \mathrm{~nm}$ using a microplate reader (Synergy HT, BioTek, Swindon, United Kingdom). Ascorbic acid $(1.25 \mathrm{mg} / \mathrm{mL})$ was used as a positive control, while the reaction mixture without any sample was used as a negative control. ROS scavenging activity percentage was calculated as follows:

$$
\% \text { activity }=(\mathrm{A}-\mathrm{B}) / \mathrm{A} \times 100
$$

where $\mathrm{A}$ is the absorbance of the negative control and B is the absorbance of the tested sample. Analyses were performed in three replicates.

\subsection{Statistical Analysis}

Results of DPPH assay are reported as mean \pm standard deviation for the values with a normal distribution (or interquartile range and median for the values that did not adhere to the Gaussian distribution). For the data with normal distribution, an analysis of variance (ANOVA) was performed, considering the compound and its concentration as fixed factors, while the inhibition percentage as the dependent variable. The significance criterion was set to $p<0.05$.

Author Contributions: F.S.R.d.C., J.C., A.G.: conceptualization, investigation and writing original draft preparation, data analysis; E.B.: antioxidant activity; C.B. and A.T.: writing-review \& editing.

Funding: Research partially funded by the project "Implementation of the FAO International Treaty on Plant Genetic Resources for Food and Agriculture" of the Ministry of Agriculture, Alimentation and Forestry Policies, aimed at research and experimentation supporting the collection, characterization and evaluation of plant genetic resources.

Conflicts of Interest: The authors declare no conflict of interest. 


\section{References}

1. Dudareva, N. Biochemical and Molecular Genetic Aspects of Floral Scents. Plant Physiol. 2000, 122, 627-634. [CrossRef] [PubMed]

2. Knudsen, J.T.; Eriksson, R.; Gershenzon, J.; Ståhl, B. Diversity and Distribution of Floral Scent. Bot. Rev. 2006, 72, 1-120. [CrossRef]

3. Dobson, H.E.M. Floral volatiles in insect biology. In Insect-Plant Interactions; Bernays, E., Ed.; CRC: Boca Raton, FL, USA, 1994; Volume 5, pp. 47-81.

4. Raguso, R.A. Floral Scent, Olfaction, and Scent-Driven Foraging Behavior, in Cognitive Ecology of Pollination; Chittka, L., Thomson, J.D., Eds.; Cambridge University Press: Cambridge, UK, 2001; p. 83.

5. Dodson, C.H.; Dressler, R.L.; Hills, H.G.; Adams, R.M.; Williams, N.H. Biologically Active Compounds in Orchid Fragrances. Science 1969, 164, 1243-1249. [CrossRef] [PubMed]

6. Dobson, H.E.M.; Danielson, E.M.; Van Wesep, I.D. Pollen odor chemicals as modulators of bumble bee foraging on Rosa rugosa Thunb. (Rosaceae). Plant. Spec. Biol. 1999, 14, 153-166. [CrossRef]

7. Menzel, R. Learning in honey bees in an ecological and behavioral context. In Experimental Behavioral Ecology; Hölldobler, B., Lindauer, M., Eds.; Fischer: Stuttgart, Germany, 1985; pp. 55-74.

8. Waser, N.M. Flower Constancy: Definition, Cause, and Measurement. Am. Nat. 1986, 127, $593-603$. [CrossRef]

9. Pellmyr, O. Three pollination morphs in Cimicifuga simplex; incipient speciation due to inferiority in competition. Oecologia 1986, 68, 304-307. [CrossRef]

10. Grant, V. Modes and origins of mechanical and ethological isolation in angiosperms. Proc. Natl. Acad. Sci. USA 1994, 91, 3-10. [CrossRef]

11. Friedman, M.; Henika, P.R.; Mandreil, R.E. Bactericidal activities of plant essential oils and some of their isolated constituents against Campylobacter jejuni, Escherichia coli, Listeria mono-cytogenes, and Salmonella enterica. J. Food Protect. 2002, 65, 1545-1560. [CrossRef]

12. Hammer, K.A.; Carson, C.F.; Riley, T.V. Antifungal activity of the components of Melaleuca alternifolia (tea tree) oil. J. Appl. Microbiol. 2003, 95, 853-860. [CrossRef]

13. Huber, F.K.; Kaiser, R.; Sauter, W.; Schiestl, F.P. Floral scent emission and pollinator attraction in two species of Gymnadenia (Orchidaceae). Oecologia 2005, 142, 564-575. [CrossRef]

14. Christenhusz, M.J.; Byng, J.W. The number of known plants species in the world and its annual increase. Phytotaxa 2016, 261, 201. [CrossRef]

15. Kaiser, R. The Scent of Orchids: Olfactory and Chemical Investigations; Elsevier: Amsterdam, The Netherlands, 1993.

16. Salzmann, C.C.; Nardella, A.M.; Cozzolino, S.; Schiestl, F.P. Variability in floral scent in rewarding and deceptive orchids: The signature of pollinator-imposed selection? Ann. Bot. 2007, 100, 757-765. [CrossRef] [PubMed]

17. Schiestl, F.P.; Peakall, R.; Ibarra, F.; Francke, W.; Mant, J.G.; Schulz, C.; Franke, S. The Chemistry of Sexual Deception in an Orchid-Wasp Pollination System. Science 2003, 302, 437-438. [CrossRef] [PubMed]

18. Pridgeon, A.M.; Cribb, P.J.; Chase, M.W.; Rasmussen, F. Genera Orchidacearum, Vol. II: Orchidoideae (Part I); OUP: Oxford, UK, 2001.

19. Pellegrino, G.; Bellusci, F.; Musacchio, A. Double floral mimicry and the magnet species effect in dimorphic co-flowering species, the deceptive orchid Dactylorhiza sambucina and rewarding Viola aethnensis. Preslia 2008, 80, 411-422.

20. Bartolucci, F.; Peruzzi, L.; Galasso, G.; Albano, A.; Alessandrini, A.; Ardenghi, N.M.G.; Astuti, G.; Bacchetta, G.; Ballelli, S.; Banfi, E.; et al. An updated checklist of the vascular flora native to Italy. Plant Biosyst. 2018, 152, 179-303. [CrossRef]

21. Cozzolino, S.; Schiestl, F.P.; Müller, A.; De Castro, O.; Nardella, A.M.; Widmer, A. Evidence for pollinator sharing in Mediterranean nectar-mimic orchids: Absence of premating barriers? Proc. R. Soc. B Boil. Sci. 2005, 272, 1271-1278. [CrossRef]

22. Schiestl, F.P.; Ayasse, M.; Paulus, H.F.; Löfstedt, C.; Hansson, B.S.; Ibarra, F.; Francke, W. Orchid pollination by sexual swindle. Nature 1999, 399, 421. [CrossRef]

23. Dafni, A.; Ivri, Y.; Brantjes, N.B.M. Pollination of Serapias vomeracea Briq. (Orch.) by imitation of holes for sleeping solitary male bees (Hym.). Acta Bot. Neerl. 1981, 30, 69-73. [CrossRef] 
24. van der Cingel, N.A. An Atlas of Orchid Pollination: European Orchids; A.A. Balkema Publishers: Rotterdam, The Netherlands, 1995.

25. Pellegrino, G.; Luca, A.; Bellusci, F.; Musacchio, A. Comparative analysis of floral scents in four sympatric species of Serapias L. (Orchidaceae): Clues on their pollination strategies. Plant Syst. Evol. 2012, 298, 1837-1843. [CrossRef]

26. Adams, R. Identification of Essential Oil Components by Gas Chromatography/Mass Spectrometry, 4th ed.; Allured Publishing Corporation: Carol Stream, IL, USA, 2007.

27. Oliveros, J.C. (2007-2015) Venn'sy. An Interactive Tool for Comparing Lists with Venn's Diagrams. Available online: http://bioinfogp.cnb.csic.es/tools/Venn\T1\textquoterightsy/index.html (accessed on 19 June 2019).

28. Manzo, A.; Panseri, S.; Vagge, I.; Giorgi, A. Volatile Fingerprint of Italian Populations of Orchids Using Solid Phase Microextraction and Gas Chromatography Coupled with Mass Spectrometry. Molecules 2014, 19, 7913-7936. [CrossRef]

29. Robustelli della Cuna, F.S.; Boselli, C.; Papetti, A.; Mannucci, B.; Calevo, J.; Tava, A. Composition of Volatile Fraction from Inflorescences and Leaves of Dendrobium moschatum (Orchidaceae). Nat. Prod. Commun. 2018, 13, 93-96. [CrossRef]

30. Schiestl, F.P.; Ayasse, M.; Paulus, H.F.; Löfstedt, C.; Hansson, B.S.; Ibarra, F.; Francke, W. Sex pheromone mimicry in the early spider orchid (Ophrys sphegodes): Patterns of hydrocarbons as the key mechanism for pollination by sexual deception. J. Comp. Physiol. A 2000, 186, 567-574. [CrossRef] [PubMed]

31. Mant, J.; Brändli, C.; Vereecken, N.J.; Schulz, C.M.; Francke, W.; Schiestl, F.P. Cuticular hydrocarbons as sex pheromone of the bee Colletes cunicularius and the key to its mimicry by the sexually deceptive orchid, Ophrys exaltata. J. Chem. Ecol. 2005, 31, 1765-1787. [CrossRef] [PubMed]

32. Eigenbrode, S.D.; Espelie, K.E. Effects of Plant Epicuticular Lipids on Insect Herbivores. Annu. Rev. Entomol. 1995, 40, 171-194. [CrossRef]

33. Mohd-Hairul, A.R.; Namasivayam, P.; Lian, G.E.C.; Abdullah, J.O. Terpenoid, Benzenoid, and Phenylpropanoid Compounds in the Floral Scent of Vanda Mimi Palmer. J. Plant Boil. 2010, 53, 358-366. [CrossRef]

34. Steiner, K.E.; Kaiser, R.; Dötterl, S. Strong phylogenetic effects on floral scent variation of oil-secreting orchids in South Africa. Am. J. Bot. 2011, 98, 1663-1679. [CrossRef]

35. Lind, H.; Lindeborg, M. Lepidopterans as presumptive pollinators of Anacamptis pyramidalis. Entomol. Tidskr. 1989, 110, 156-160.

36. Lind, H. Occurrence, population and fruit setting in Anacamptis pyramidalis on OÖland, Sweden. Sven. Bot. Tidskr. 1992, 86, 329-336.

37. Lind, H. Lepidoptera-Important Long-Distance Pollinators for Plants in Fragmented Habitats. Sven. Bot. Tidskr. 1994, 88, 185-187.

38. Proctor, M.; Yeo, P.; Lack, A. The Natural History of Pollination, 1st ed.; HarperCollins: London, UK, 1996.

39. Tava, A.; Cecotti, R.; Confalonieri, M. Characterization of the volatile fraction of Nigritella nigra (L.) Rchb. F. (Orchidaceae), a rare species from the Central Alps. J. Essent. Oil Res. 2012, 24, 39-44. [CrossRef]

40. Politeo, O.; Jukic, M.; Milos, M. Chemical composition and antioxidant activity of free volatile aglycones from Laurel (Laurus nobilis L.) compared to its essential oil. Croat. Chem. Acta 2007, 80, 121-126.

41. Zhao, J.; Jiang, L.; Tang, X.; Peng, L.; Li, X.; Zhao, G.; Zhong, L. Chemical Composition, Antimicrobial and Antioxidant Activities of the Flower Volatile Oils of Fagopyrum esculentum, Fagopyrum tataricum and Fagopyrum Cymosum. Molecules 2018, 23, 182. [CrossRef] [PubMed]

42. Yanishlieva, N.V.; Marinova, E.M.; Gordon, M.H.; Raneva, V.G. Antioxidant activity and mechanism of action of thymol and carvacrol in two lipid systems. Food Chem. 1999, 64, 59-66. [CrossRef]

43. Andrade, M.A.; das Graças Cardoso, M.; de Andrade, J.; Silva, L.F.; Teixeira, M.L.; Valério Resende, J.M.; da Silva Figueiredo, A.C.; Barroso, J.G. Chemical composition and antioxidant activity of essential oils from Cinnamodendron dinisii Schwacke and Siparuna guianensis Aublet. Antioxidants 2013, 2, 384-397. [CrossRef]

44. Andersson, S.; Nilsson, L.A.; Groth, I.; Bergström, G. Floral scents in butterfly-pollinated plants: Possible convergence in chemical composition. Bot. J. Linn. Soc. 2002, 140, 129-153. [CrossRef]

45. Schiestl, F.P.; Cozzolino, S. Evolution of sexual mimicry in the orchid subtribe orchidinae: The role of preadaptations in the attraction of male bees as pollinators. BMC Evol. Boil. 2008, 8, 27. [CrossRef]

46. G.I.R.O.S. Gruppo Italiano Ricerca Orchidee Spontanee. Available online: http://www.giros.it/forum/ viewtopic.php?f=7\&t=1498 (accessed on 9 January 2019). 
47. El Mokni, R.; Hammami, S.; Dall'Acqua, S.; Peron, G.; Faidi, K.; Braude, J.P.; Sebei, H.; El Aouni, M.H. Chemical composition, antioxidant and cytotoxic activities of essential oil of the inflorescence of Anacamptis coriophora subsp. fragrans (Orchidaceae) from Tunisia. Nat. Prod. Commun. 2016, 11, 857-860. [CrossRef]

48. Dormont, L.; Delle-Vedove, R.; Bessiere, J.-M.; Schatz, B. Floral scent emitted by white and coloured morphs in orchids. Phytochemistry 2014, 100, 51-59. [CrossRef]

49. Chase, M.W.; Cameron, K.M.; Freudenstein, J.V.; Pridgeon, A.M.; Salazar, G.; Berg, C.V.D.; Schuiteman, A. An updated classification of Orchidaceae. Bot. J. Linn. Soc. 2015, 177, 151-174. [CrossRef]

50. Carlson, D.A.; Roan, C.S.; Yost, R.A.; Hector, J. Dimethyl disulphide derivatives of long chain alkenes, alkadienes and alkatrienes for gas chromatography/mass spectrometry. Anal. Chem. 1989, 61, 1564-1571. [CrossRef]

51. Dool, H.V.D.; Kratz, P.D. A generalization of the retention index system including linear temperature programmed gas_Liquid partition chromatography. J. Chromatogr. A 1963, 11, 463-471. [CrossRef]

52. Bari, E.; Arciola, C.R.; Vigani, B.; Crivelli, B.; Moro, P.; Marrubini, G.; Sorrenti, M.; Catenacci, L.; Bruni, G.; Chlapanidas, T.; et al. In Vitro Effectiveness of Microspheres Based on Silk Sericin and Chlorella vulgaris or Arthrospira platensis for Wound Healing Applications. Materials 2017, 10, 983. [CrossRef] [PubMed]

53. Bari, E.; Perteghella, S.; Marrubini, G.; Sorrenti, M.; Catenacci, L.; Tripodo, G.; Mastrogiacomo, M.; Mandracchia, D.; Trapani, A.; Faragò, S.; et al. In vitro efficacy of silk sericin microparticles and platelet lysate for intervertebral disk regeneration. Int. J. Boil. Macromol. 2018, 118, 792-799. [CrossRef]

54. Chlapanidas, T.; Faragò, S.; Lucconi, G.; Perteghella, S.; Galuzzi, M.; Mantelli, M.; Avanzini, M.A.; Tosca, M.C.; Marazzi, M.; Vigo, D.; et al. Sericins exhibit ROS-scavenging, anti-tyrosinase, anti-elastase, and in vitro immunomodulatory activities. Int. J. Boil. Macromol. 2013, 58, 47-56. [CrossRef]

Sample Availability: Samples of the compounds are not available from the authors.

(C) 2019 by the authors. Licensee MDPI, Basel, Switzerland. This article is an open access article distributed under the terms and conditions of the Creative Commons Attribution (CC BY) license (http://creativecommons.org/licenses/by/4.0/). 